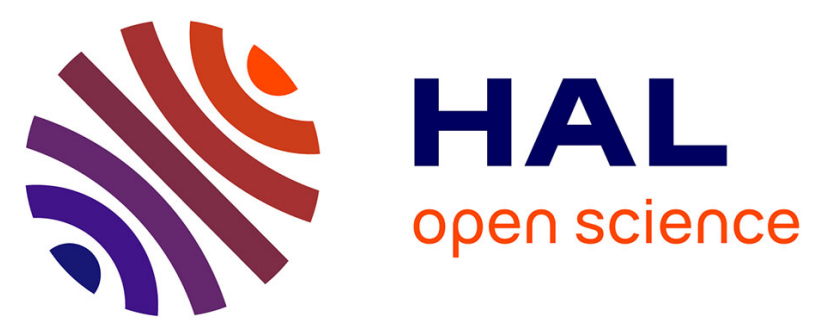

\title{
Assessment of an effective quasirelativistic methodology designed to study astatine chemistry in aqueous solution
} Julie Champion, Mahamadou Seydou, Andrea Sabatié-Gogova, Eric Renault, Gilles F Montavon, Nicolas Galland

\section{- To cite this version:}

Julie Champion, Mahamadou Seydou, Andrea Sabatié-Gogova, Eric Renault, Gilles F Montavon, et al.. Assessment of an effective quasirelativistic methodology designed to study astatine chemistry in aqueous solution. Physical Chemistry Chemical Physics, 2011, 13, pp.14984-14992. 10.1039/C1CP20512A . in2p3-01586060

\section{HAL Id: in2p3-01586060 \\ https://hal.in2p3.fr/in2p3-01586060}

Submitted on 12 Sep 2017

HAL is a multi-disciplinary open access archive for the deposit and dissemination of scientific research documents, whether they are published or not. The documents may come from teaching and research institutions in France or abroad, or from public or private research centers.
L'archive ouverte pluridisciplinaire HAL, est destinée au dépôt et à la diffusion de documents scientifiques de niveau recherche, publiés ou non, émanant des établissements d'enseignement et de recherche français ou étrangers, des laboratoires publics ou privés.

\section{(1) (1) $\$$}

Distributed under a Creative Commons Attribution - NonCommercial - NoDerivatives 44.0 


\title{
Assessment of an effective quasirelativistic methodology designed to study astatine chemistry in aqueous solution $\uparrow$
}

\author{
Julie Champion, ${ }^{a, b}$ Mahamadou Seydou, ${ }^{a, b}$ Andrea Sabatié-Gogova, ${ }^{b}$ Eric Renault, ${ }^{a}$ Gilles Montavon ${ }^{* b}$ \\ and Nicolas Galland $* a$
}

\author{
s Received (in XXX, XXX) Xth XXXXXXXXX 200X, Accepted Xth XXXXXXXXX 200X \\ First published on the web Xth $X X X X X X X X X 200 X$ \\ DOI: $10.1039 / b 000000 x$
}

\begin{abstract}
A cost-effective computational methodology designed to study astatine (At) chemistry in aqueous solution has been established. It is based on two-component spin-orbit density functional 10 theory calculations and solvation calculations using the conductor-like polarizable continuum model in conjunction with specific astatine cavities. Theoretical calculations are confronted with experimental data measured for complexation reactions between metallic forms of astatine ( $\mathrm{At}^{+}$ and $\left.\mathrm{AtO}^{+}\right)$and inorganic ligands $\left(\mathrm{Cl}^{-}, \mathrm{Br}^{-}\right.$and $\left.\mathrm{SCN}^{-}\right)$. For each reaction, both 1:1 and 1:2 complexes are evidenced. The experimental trends regarding the thermodynamic constants $(K)$ can 15 be reproduced qualitatively and quantitatively. The mean signed error on computed $\log K$ values is -0.4 , which corresponds to a mean signed error smaller than $1 \mathrm{kcal} \mathrm{mol}^{-1}$ on free energies of reaction. Theoretical investigations show that the reactivity of cationic species of astatine is highly sensitive to spin-orbit coupling and solvent effects. At the moment, the presented computational methodology appears to be the only tool to gain an insight into astatine chemistry at a molecular 20 level.
\end{abstract}

\section{Introduction}

Astatine (At) is the heaviest halogen (element 85), found below iodine in the periodic table of the elements. One of its isotopes, At-211, is a promising candidate as a therapeutic ${ }_{25}$ agent in nuclear medicine. ${ }^{1,2}$ It is a $100 \%$ alpha emitter, with a half life of $7.2 \mathrm{~h}$. Sufficiently high energy X-rays accompany these characteristic alpha emissions, allowing external At-211 distribution imaging. ${ }^{3}$ Monitoring the X-ray emissions provides useful concerning the dosimetry, tumor 30 accumulation and normal tissue deposition of At-211-labeled radiopharmaceuticals. Two recent reviews summarize the use of astatine as a radiotherapeutic agent. ${ }^{4,5}$ Although much of the chemistry described for halogens is applicable to astatine, the chemical similarities between astatine and its nearest 35 halogen neighbor, iodine, is not always obvious. Indeed, At chemistry in aqueous solution is not well understood. Astatine is one of the most difficult elements to investigate from a chemist's point of view: it is a rare element since there is no stable isotope of astatine (production is with accelerators 40 capable of accelerating alpha particles to high energies), with its longest-lived isotope having a half-life of $8.3 \mathrm{~h}$. It can be considered as an invisible element since all investigations were derived from radiochemical studies at ultra-trace concentrations (typically smaller than $10^{-10} \mathrm{~mol} / \mathrm{L}$ ) and no

${ }_{45}$ spectroscopic tools can be used to evaluate astatine chemistry at the molecular level.

From a theoretical point of view, atomic astatine and few small species containing astatine were mainly studied as simple model systems to investigate the reliability of quantum ${ }_{50}$ chemistry methods. ${ }^{6-20}$ There is currently a growing interest in using relativistic methods for higher-accuracy calculations.
The most accurate approach to incorporate relativity would be to perform four-component $(4 c)$ calculations based on the exact relativistic Hamiltonian. The straightforward way to 55 construct the relativistic many-electron Hamiltonian is to augment the one-electron Dirac operator with the Coulomb or Breit operator as a two-electron term. Hartree-Fock founded (DHF) and Kohn-Sham (DKS) methods with a fourcomponent Hamiltonian have become familiar ${ }^{21-23}$ but they 60 have an intrinsically big computational cost and their use is still limited to small molecules, mostly for benchmarking purposes. While there has been considerable progress in reducing the cost of such calculations, ${ }^{18,24}$ the applicability of the four-component theory to large molecular systems is 65 hindered mainly by the comparatively early stage of development of the relevant algorithms and codes. ${ }^{25}$ As an alternative approach, several two-component (2c) quasirelativistic approximations have been proposed and applied to chemically interesting systems containing heavy 70 elements. Accurate descriptions of relativistic effects could be obtained with the familiar Douglas-Kroll (DKn) approach, involving a transformation to the $n$th order of the Dirac Hamiltonian, ${ }^{13,26}$ or using the $n$th order regular approximation (ZORA, FORA) of the exact relativistic Hamiltonian. ${ }^{27,}{ }^{28}$ For 75 large molecular systems, the most appealing quasirelativistic approach is to switch to relativistic effective core potentials (RECPs) or pseudopotentials (PPs). Approximate calculations based on RECPs or PPs are known to successfully yield results that are very close to the all-electron results without 80 introducing any empirical parameters. ${ }^{12,} 16,20,29,30$ In this context, several theoretical studies on At, HAt and At 2 species have been conducted, in order to check various relativistic and quasirelativistic computational methods. The theoretical interest in astatine and its compounds is related to the fact that 
these species are subject to large relativistic effects, notably spin-orbit (SO) coupling ( $c f$. Table S1 in Supplementary Information). High level calculations predict that the SO interactions reduce by one third the astatine's electron affinity

${ }_{5}(E A)$ and the dissociation energy $\left(D_{e}\right)$ of HAt. In the case of $\mathrm{At}_{2}$, the SO coupling contribution to $D_{e}$ is greater than the value of the dissociation energy; the vibrational harmonic frequency $\left(\omega_{e}\right)$ is also strongly affected (almost $50 \%$ reduction).

10 Apart from these fundamental studies, no theoretical investigation has been reported concerning one of the few astatine compounds that are experimentally evidenced. ${ }^{31-39}$ There is an actual need for a very cost-effective method that enables to study medium size species without neglecting the

15 important SO effects specific to astatine. In this work, we first present experimental results on the complexation properties of the cationic forms of astatine in solution. Recently, $\mathrm{At}^{+}$and $\mathrm{AtO}^{+}$species (jointly referred to as $\left.\mathrm{At}(\mathrm{x})^{+}\right)$have been identified as the major chemical forms of astatine in acidic 20 aqueous solution. ${ }^{40}$ Both species were mixed with inorganic ligands, namely $\mathrm{Cl}^{-}$and $\mathrm{Br}^{-}$, and the complexation constants were measured using a competition method. These findings, and those of a previous study of $\operatorname{At}(\mathrm{x})^{+}$reactions with $\mathrm{SCN}^{-}$ species, ${ }^{41}$ were used in a second step to support an original 25 computational methodology designed to study the astatine chemistry in solution. The theoretical approach has particularly low computational demand because it involves (i) two-component quasirelativistic density functional calculations performed in gas phase, (ii) solvation calculations 30 based on a efficient continuum model, and (iii) all calculations use a relativistic pseudopotential for At atom.

\section{Materials and experimental methodology}

\section{Reagents and production of astatine-211}

All reagents were of analytical grade or better. The solutions 35 were prepared using Milli-Q water and all experiments were conducted in air-conditioned laboratories. At-211 was produced via the ${ }^{209} \operatorname{Bi}(\alpha, 2 \mathrm{n})^{211}$ At nuclear reaction at the cyclotron CEMTHI in Orleans, France. A bismuth target is irradiated for two hours by a $28 \mathrm{MeV}$ alpha external beam. ${ }^{42}$

40 After irradiation of the target, At-211 is isolated using a 'wet' process developed by Alliot et al. ${ }^{43}$ resulting in a $500 \mu \mathrm{L}$ solution of $0.1 \mathrm{~mol} / \mathrm{L} \mathrm{NaOH}$ with a specific volume activity close to $1 \mathrm{MBq} / \mathrm{mL}$. The sample's purity was verified and quantified by gamma ray spectroscopy with a high purity ${ }_{45}$ germanium (HPGe) detector. The activity of the stock astatine solution was determined using the X-rays from both Po-211 and At-211, as well as the $687.0 \mathrm{keV} \gamma$-rays from At-211. ${ }^{44}$

\section{Competition method}

$\mathrm{At}^{+}$was prepared in $0.1 \mathrm{~mol} / \mathrm{L} \mathrm{HClO}_{4}$ and $\mathrm{NaClO}_{4}$ solution ${ }_{50}(p H=1$ and $\mathrm{E} \sim 0.6 \mathrm{~V} v s$. NHE $)$ and $\mathrm{AtO}^{+}$with a mixture of $5 \quad 10^{-3} \mathrm{~mol} / \mathrm{L} \quad \mathrm{K}_{2} \mathrm{Cr}_{2} \mathrm{O}_{7}, \quad 0.1 \mathrm{~mol} / \mathrm{L} \quad \mathrm{HClO}_{4}$ and $0.1 \mathrm{~mol} / \mathrm{L}$ $\mathrm{NaClO}_{4} \quad(p H=1$ and $\mathrm{E} \sim 1 \mathrm{~V}$ vs. NHE $) .{ }^{45-47}$ The stability constants between inorganic ligands $\left(\mathrm{Cl}^{-}, \mathrm{Br}^{-}\right)$and cationic species of astatine $\left(\operatorname{At}(\mathrm{x})^{+}\right)$were determined using a ${ }_{55}$ competition method proposed by Champion et al. ${ }^{41}$ and previously used with the $\mathrm{SCN}^{-}$anion. The method consists in studying the distribution of astatine between aqueous phase and toluene as a function of ligand concentration. The system $(5 \mathrm{~mL}$ of organic phase and $5 \mathrm{~mL}$ of aqueous phase were 60 brought into contact in Pyrex tubes) is first equilibrated before astatine addition. Two hours of shaking were sufficient to achieve distribution equilibrium of $\mathrm{At}(\mathrm{x})^{+}$between the phases. After phase separation, an aliquot of aqueous and organic phases were withdrawn to derive the distribution coefficient ${ }_{65} D$ :

$$
D=\frac{V_{\text {org }} \times A_{\text {org }}}{V_{\text {aq }} \times A_{\text {aq }}}
$$

where $V_{\text {org }}$ and $V_{\text {aq }}$ represent the volume of the given phase, and $A_{\text {org }}$ and $A_{\text {aq }}$ define the isotope's activities in the organic and aqueous phases, respectively. These activities were 70 measured using liquid scintillation counting with a Packard $2550 \mathrm{TR} / \mathrm{AB}$ Liquid Scintillation analyzer with the Ultima Gold LLT scintillation liquid. ${ }^{40}$ Uncertainties associated with $D$ values were calculated according to the following equation:

$$
\sigma_{D}=D \sqrt{\frac{\sigma_{A_{\text {org }}}^{2}}{A_{\text {org }}}+\frac{\sigma_{A_{\text {aq }}}^{2}}{A_{\text {aq }}}+\frac{\sigma_{V_{\text {org }}}^{2}}{V_{\text {org }}}+\frac{\sigma_{V_{\text {aq }}}^{2}}{V_{\text {aq }}}}
$$

75 At least three experiments were performed in parallel under the chosen experimental conditions. The average values are given with uncertainties corresponding to a $95 \%$ confidence interval.

\section{Determination of the stability constants}

${ }_{80}$ Considering the $p K a$ values of $\mathrm{HCl}$ and $\mathrm{HBr},{ }^{48}$ dissolved $\mathrm{NaCl}$ and $\mathrm{NaBr}$ salts yield in the experimental conditions $\mathrm{Cl}^{-}$and $\mathrm{Br}^{-}$species which interact with $\mathrm{At}(\mathrm{x})^{+}$as follows:

$$
\mathrm{At}(\mathrm{x})^{+}+m \mathrm{X}^{-} \stackrel{\beta_{m}}{\rightleftharpoons} \mathrm{At}(\mathrm{x}) \mathrm{X}_{m}^{1-m}
$$

with $\mathrm{X}^{-}$corresponding to $\mathrm{Cl}^{-}$or $\mathrm{Br}^{-}$and $\mathrm{At}(\mathrm{x}) \mathrm{X}_{m}^{1-m}$ to the 85 complex formed with a $1: \mathrm{m}$ stoichiometry. The stability constant associated to the formation of the complex, $\beta_{\mathrm{m}}$, is given by:

$$
\beta_{m}=\frac{\left(\mathrm{At}(\mathrm{x}) \mathrm{X}_{m}^{1-m}\right)}{\left(\operatorname{At}(\mathrm{x})^{+}\right)\left(\mathrm{X}^{-}\right)^{m}}
$$

where the data in parenthesis represent the activities of the 90 species at equilibrium. Without any ligand in solution, astatine distribution $D_{0}$ can be expressed by:

$$
D_{0}=\frac{\left[\overline{A t(x)^{+}}\right]}{\left[A t(x)^{+}\right]}
$$

where $\overline{A t(x)^{+}}$represents astatine species in organic solution and $A t(x)^{+}$the species in aqueous solution. In the presence of ${ }_{95} \mathrm{X}^{-}$ligands in solution, the distribution of astatine varies and depends on the concentration of the formed complexes: 


$$
D=\frac{\left[\overline{A t(x)^{+}}\right]}{\left[\operatorname{At}(x)^{+}\right]+\sum_{n=1}^{m}\left[\operatorname{At}(x) X_{n}^{1-n}\right]}
$$

Several complexes with 1:n stoichiometry can be present in aqueous solution. Thus, the astatine distribution between aqueous and organic phases can be expressed as a function of 5 the ligand concentration in aqueous solution:

$$
D=\frac{D_{0}}{1+\sum_{n} \beta_{n}\left[\mathrm{X}^{-}\right]^{n}}
$$

The number and the nature of the formed complexes together with the stability constants were derived by a fitting procedure of titration curves, i.e. by analyzing the dependence of $D$ 10 values on $\mathrm{X}^{-}$concentration. We used the same procedure as described by Champion et al. ${ }^{41}$ the modeling involving the CHESS calculation code. ${ }^{49}$ All the thermodynamic constants are given for $298.15 \mathrm{~K}, 1 \mathrm{~mol} / \mathrm{L}$ standard state and extrapolated at null ionic strength using the Truncated Davies 15 equation. ${ }^{50}$

\section{Computational methodology}

\section{SODFT method and basis sets}

The application of density functional theory (DFT) appears particularly attractive for heavy-element systems due to the 20 computational expediency and the implicit inclusion of electron correlation effects. However, relativistic effects become as important as electron correlation effects for heavyelements and should be treated on the same footing. One may distinguish between electron spin-independent (scalar) and ${ }_{25}$ spin-dependent effects. The leading spin-dependent effect is the coupling between electron spin and orbital momentum (SO coupling), which in particular for heavy p-elements may be of similar size as scalar relativistic effects. The spin-orbit DFT (SODFT) approach implemented in the NWChem 30 programs package ${ }^{51}$ has been successfully used to investigate relativistic effects on molecules containing halogen elements. ${ }^{30,52,53}$ This approach takes advantage of RECPs and PPs, which replace inner-core electrons and introduce scalar and, optionally, spin-orbit terms into the variational treatment 35 of the one-electron spin-orbit operator, to include SO effects. Furthermore, the non-relativistic formalism operating with orbitals represented by real numbers is extended to a twocomponent formalism with complex orbitals (spinors). There can be many variations in the form of RECPs and PPs, the 40 present PPs are expressed by the following form:

$$
V_{P P}(r)=-\frac{Z_{e f f}}{r}+\sum_{l j k} B_{l j}^{k} \exp \left(-\beta_{l j}^{k} r^{2}\right) \mathbf{P}_{l j}
$$

where $Z_{\text {eff }}$ is the charge of the inner-core. The sum runs over a Gaussian expansion (index $k$ ) of semi-local short-range radial potentials which are different for different orbital angular${ }_{45}$ momentum quantum numbers $l$ and, for a given $l$, for the two total one-electron angular-momentum quantum numbers $j=l \pm 1 / 2\left(\mathbf{P}_{l j}\right.$ is the projector onto the complete space of functions with angular symmetry $l, j$ around the core under study). The parameters $B_{l j k}$ and $\beta_{l j k}$ are adjusted so that $V_{P P}$ in 50 two-component valence-only atomic calculations reproduces, as closely as possible, a set of all-electron reference energies.

We have selected for our calculations the widely used B3LYP ${ }^{54-57}$ density functional. Relativistic effects were introduced using the (small-core) scalar or spin-dependent ${ }_{55}$ ECP60MDF pseudopotential generated by the Stuttgart/Cologne group for At atom. ${ }^{12}$ At first, we opted to the aug-cc-pVDZ-PP (AVDZ) basis set $^{12}$ to describe the 25 valence electrons. However, this basis set has been optimized using one-component approach and is not appropriate to ${ }_{60}$ describe the SO coupling, in particular on the $5 \mathrm{p}$ and $5 \mathrm{~d}$ innershells. As previously demonstrated for other basis sets, ${ }^{17}$ adding only few functions with exponents in the range of the inner-shells was sufficient to allow for the splitting of the inner $\mathrm{p}$-shell to an energetically lower lying more compact $\mathrm{p}_{1 / 2}$ ${ }_{65}$ and a higher lying less compact $\mathrm{p}_{3 / 2}$ subshell, and similarly that of the d-shell to $d_{3 / 2}$ and $d_{5 / 2}$. The resulting basis set is termed mAVDZ ( $c f$. Supplementary Information). The performance of the two-component B3LYP calculations in conjunction with ECP60MDF and MAVDZ basis set have 70 been tested on the case of At, HAt and $\mathrm{At}_{2}$ reference species. Calculated spectroscopic constants are presented in Table 1 and compared to the results of high level calculations. We define the spin-orbit effects $(\Delta \mathrm{SO})$ as the difference between scalar and quasirelativistic values calculated B3LYP/mAVDZ 75 level of theory. Considering all the studied properties (and the

\begin{tabular}{|c|c|c|c|}
\hline & & Reference values ${ }^{a}$ & B3LYP/mAVDZ \\
\hline \multirow[t]{4}{*}{ At } & $I E(\mathrm{eV})$ & 9.21 & 9.37 \\
\hline & $\triangle S O$ & -0.82 & -0.74 \\
\hline & $E A(e V)$ & 2.30 & 2.43 \\
\hline & $\triangle S O$ & -0.80 & -0.76 \\
\hline \multirow[t]{6}{*}{$\mathrm{HAt}^{b}$} & $D_{e}(\mathrm{eV})$ & 2.36 & 2.37 \\
\hline & $\triangle S O$ & -0.71 & -0.70 \\
\hline & $\omega_{e}\left(\mathrm{~cm}^{-1}\right)$ & 1962 & 1945 \\
\hline & $\triangle S O$ & -194 & -151 \\
\hline & $R_{e}(\AA)$ & 1.74 & 1.75 \\
\hline & $\triangle S O$ & 0.03 & 0.03 \\
\hline \multirow[t]{6}{*}{$\mathrm{At}_{2}$} & $D_{e}(e V)$ & 0.63 & 0.62 \\
\hline & $\triangle S O$ & -1.07 & -0.98 \\
\hline & $\omega_{e}\left(\mathrm{~cm}^{-1}\right)$ & 107 & 104 \\
\hline & $\triangle S O$ & -44 & -45 \\
\hline & $R_{e}(\AA)$ & 3.06 & 3.09 \\
\hline & $\triangle S O$ & 0.17 & 0.17 \\
\hline
\end{tabular}

Table 1 Spectroscopic constants of At, HAt and $\mathrm{At}_{2}$ species calculated at B3LYP/mAVDZ level of theory

a Average values calculated from results of high level calculations 80 reported in literature (Ref. 8, 9, 13, 14, 16, 52, 61, 62). ${ }^{b}$ aug-cc-pVDZ basis set was used for $\mathrm{H}$ atom (Ref. 58, 59). 
magnitude of the SO effects) for At, HAt and $\mathrm{At}_{2}$ species, the overall $\mathrm{B} 3 \mathrm{LYP} / \mathrm{mAVDZ}$ results is in remarkable agreement with the reference values. The agreement is especially good for the diatomic species: in the case of $\mathrm{At}_{2}$, the computed $D_{e}$, $5 \omega_{e}$ and $R_{e}$ values are, respectively, $0.62 \mathrm{eV}, 104 \mathrm{~cm}^{-1}$ and $3.09 \AA$ while the results of reference high level calculations are centered around $0.63 \mathrm{eV}, 107 \mathrm{~cm}^{-1}$ and $3.06 \AA$. This is very encouraging in view of building a cost-effective methodology to study astatine chemistry.

10 In the following study of $\operatorname{At}(\mathrm{x})^{+}, \mathrm{X}^{-}$and $\operatorname{At}(\mathrm{x}) \mathrm{X}_{m}^{1-m}(\mathrm{X}=\mathrm{Cl}$, $\mathrm{Br}$ and $\mathrm{SCN}$ ) species, the mAVDZ basis set was used in conjunction with the aug-cc-pVDZ-PP basis set for $\mathrm{Br}$ atom ${ }^{12}$ and the aug-cc-pVDZ basis sets for $\mathrm{Cl}, \mathrm{C}, \mathrm{O}, \mathrm{S}$ and $\mathrm{N}$ atoms. ${ }^{58-60}$ The bromine ( $\left.1 \mathrm{~s}-2 \mathrm{p}\right)$ inner-cores were replaced by 15 the energy-consistent ECP10MDF pseudopotential. ${ }^{12}$ Despite the fact that relatively small basis sets were selected, our computational methodology makes use of error cancellation approaches and high-quality results are obtained (see section Computation of equilibrium constants for ligand exchange 20 reactions). Gas phase free energies of $\mathrm{At}(\mathrm{x})^{+}, \mathrm{X}^{-}$and $\operatorname{At}(\mathrm{x}) \mathrm{X}_{m}^{1-m} \quad$ species were estimated at $T=298.15 \mathrm{~K}$ and $p=1 \mathrm{~atm}$ through the computation of their energy and geometry by means of the gradient technique. Harmonic vibrational frequencies were evaluated using either analytical 25 second derivative (scalar relativistic level of theory) or by two-sided finite differences of analytical gradients (quasirelativistic level of theory). In the case of $\mathrm{At}(\mathrm{x}) \mathrm{X}_{m}^{1-m}$ species that exhibit several isomers, their Gibbs free energies have been evaluated using a Boltzmann distribution according 30 to the relation:

$$
G_{\{\mathrm{A}\}}^{\mathrm{o}}=-R T \ln \sum_{i \in\{\mathrm{A}\}} \mathrm{e}^{-G_{i}^{\mathrm{o}} / R T}
$$

where $\{A\}$ emphasizes calculation over the population of all isomers of $\mathrm{A}$.

\section{Solvation and cavity models}

${ }_{35}$ Gibbs free energies of aqueous solvation were computed for all species using the polarizable continuum model (PCM) implemented in the Gaussian 03 program package. ${ }^{63}$ While this model does not account for SO effects, the (larger) contribution of the solute geometry relaxation to the solvation

40 free energies could be evaluated by geometry optimization within the solvent model at scalar relativistic level of theory. We selected the conductor-like formulation, $\mathrm{CPCM},{ }^{64,65}$ since this model, when used in conjunction with the UAHF and UAKS cavity models, yields accurate solvation free energies ${ }^{45}$ at a very low computational cost. ${ }^{66}$ UAHF and UAKS cavities were built up using the united atom topological model applied on optimized atomic spheres. ${ }^{63,67}$ The spheres' radii depend on the nature of the element and its molecular environment (basically hybridization, formal charge and first neighbor 50 inductive effect). However, at present no parameters for astatine are included in these cavity models. Recently, we proposed to use for At a basic radius $\left(R^{0}\right)$ of $2.41 \AA$ coherent with the rest of the radii included in the UAHF (and UAKS) model. ${ }^{40}$ Because $\operatorname{At}(\mathrm{x})^{+}$and $\operatorname{At}(\mathrm{x}) \mathrm{X}_{m}^{1-m} \quad$ species display
55 structures where the At atom bears a positive charge, this leads us to define as well a charge factor $\left(\gamma_{q}\right)$ for astatine as described in UAHF and UAKS models. We propose to estimate $\gamma_{q}$ by use of the experimental value of the $\mathrm{At}^{+} / \mathrm{At}^{-}$ standard redox potential: $E^{\circ}=0.36 \pm 0.01 \mathrm{~V}\left(v s\right.$. NHE) ${ }^{40} \mathrm{As}$ 60 it will be explained using the thermodynamic cycle displayed in Scheme 1, the $r_{\mathrm{At}^{+}}$radius is the only parameter that needed to be adjusted in order to reproduce the $E^{\circ}$ value.

The Gibbs free energies of the $\mathrm{At}^{+}$reduction reaction, $\Delta G_{s}^{*}$, is related to the absolute standard reduction potential ${ }_{65}$ via the Nernst equation:

$$
E^{\circ}=-\frac{\Delta G_{s}^{*}}{n F}
$$

where $n$ is the number of electrons transferred $(n=2$ in this case) and $F$ is the Faraday constant $(96485 \mathrm{C} / \mathrm{mol})$. In addition, $\Delta G_{s}^{*}$ can be calculated from the free energy of the 70 gas-phase reaction, $\Delta G_{g}^{\circ}$, according to the relation:

$$
\Delta G_{s}^{*}=\Delta G_{g}^{\circ}+\Delta G_{s o l}^{*}\left(\mathrm{At}^{-}\right)-\Delta G_{s o l}^{*}\left(\mathrm{At}^{+}\right)
$$

where $\Delta G_{s o l}^{*}\left(\mathrm{At}^{-}\right)$and $\Delta G_{s o l}^{*}\left(\mathrm{At}^{+}\right)$are respectively the solvation free energies of $\mathrm{At}^{-}$and $\mathrm{At}^{+}$in water. $\Delta G_{g}^{\circ}$ is estimated using the electron affinity $(E A=2.30 \mathrm{eV})$ and 75 ionization energy $(I E=9.21 \mathrm{eV})$ obtained from reference high level calculations done on astatine (see Table 1). For the free electron, we have followed the electron convention based on Boltzmann statistics (the absolute value of the standard reduction potential of NHE is $4.28 \mathrm{~V}$ in this convention). ${ }^{68}$ ${ }_{80} \Delta G_{\text {sol }}^{*}\left(\mathrm{At}^{-}\right)$and $\Delta G_{\text {sol }}^{*}\left(\mathrm{At}^{+}\right)$are determined by CPCM calculations at scalar-relativistic HF/mAVDZ and $\mathrm{B} 3 \mathrm{LYP} / \mathrm{mAVDZ}$ levels of theory. These quantities rely on $r_{A t^{-}}$and $r_{\mathrm{At}^{+}}$radii, respectively. The $r_{A t^{-}}$value is not free, it must be $0.3 \AA$ shorter than the At basic radius in UAHF and ${ }_{85}$ UAKS cavity models (therefore, $r_{A t^{-}}=2.11 \AA$ ). $\Delta G_{g}^{\circ}$ and $\Delta G_{\text {sol }}^{*}\left(\mathrm{At}^{-}\right)$values are then fixed. The $r_{\mathrm{At}^{+}}$radius was adjusted in order to yield a value for $\Delta G_{\text {sol }}^{*}\left(\mathrm{At}^{+}\right)$that allows us to reproduce, using relation (10) and (11), the experimental value of $E^{\circ}$. The best agreement is obtained with $90 r_{\mathrm{At}^{+}}=1.54 \AA$, corresponding to $\gamma_{q}=-0.87 \AA$ for an astatine atom with a positive charge. Note that in the CPCM model, the solvation free energy is partitioned in different terms. The most important one is the electrostatic term. Some other terms are usually negligible ${ }^{66}$ while the dispersion and repulsion 95 terms are unavailable for astatine. Furthermore, the sum of non-electrostatic terms is generally weak with respect to the electrostatic term, especially for charged species, due to the

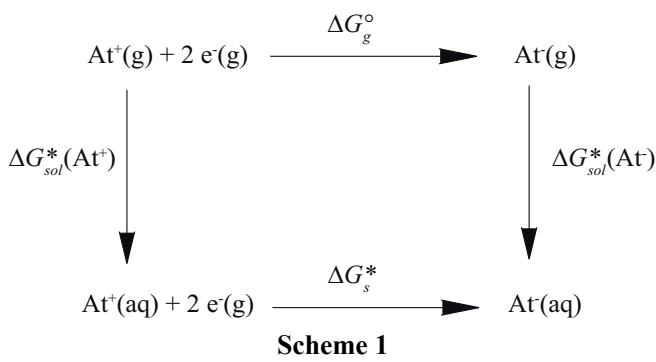




\begin{tabular}{|c|c|c|c|c|c|c|c|c|c|}
\hline \multirow{2}{*}{\multicolumn{4}{|c|}{ Equilibrium }} & \multicolumn{3}{|l|}{$\mathrm{At}^{+}$} & \multicolumn{3}{|c|}{$\mathrm{AtO}^{+}$} \\
\hline & & & & $\mathrm{Cl}^{-}$ & $\mathrm{Br}^{-}$ & $\mathrm{SCN}^{-}$ & $\mathrm{Cl}^{-}$ & $\mathrm{Br}^{-}$ & $\mathrm{SCN}^{-}$ \\
\hline $\operatorname{At}(x)^{+}$ & $+\mathrm{X}^{-}$ & $\stackrel{\log \beta_{1}}{\rightleftharpoons}$ & $\operatorname{At}(x) X$ & $1.9 \pm 0.2$ & $3.0 \pm 0.2$ & $3.8 \pm 0.2$ & $2.5 \pm 0.2$ & $2.7 \pm 0.2$ & $2.8 \pm 0.2$ \\
\hline $\operatorname{At}(x)^{+}$ & $+2 X^{-}$ & $\stackrel{\log \beta_{2}}{\rightleftharpoons}$ & $\operatorname{At}(x) X_{2}^{-}$ & $2.3 \pm 0.1$ & $4.1 \pm 0.3$ & $5.9 \pm 0.3$ & $3.0 \pm 0.3$ & $5.0 \pm 0.2$ & $5.3 \pm 0.2$ \\
\hline
\end{tabular}

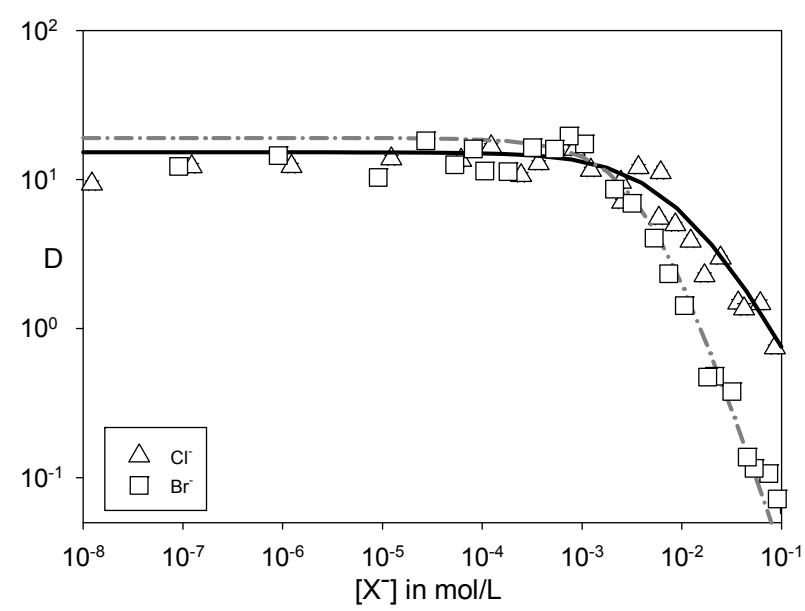

Fig. $1 \mathrm{AtO}^{+}$interaction with $\mathrm{Cl}^{-}$and $\mathrm{Br}^{-}$in a biphasic aqueous-toluene 5 system. The distribution coefficient $(D)$ is plotted as a function of ligand concentration: $\mathrm{Cl}^{-}$(triangles) and $\mathrm{Br}^{-}$(squares). The curves correspond to modeling performed with CHESS using the parameters given in Table 2 (grey dashed line for $\mathrm{AtO}^{+} / \mathrm{Cl}^{-}$system and black solid line for $\mathrm{AtO}^{+} / \mathrm{Br}$ system).

cancellation of different contributions. ${ }^{69}$ This could be exemplified on the case of the studied inorganic ligands: $\mathrm{Cl}^{-}$, $\mathrm{Br}^{-}$and $\mathrm{SCN}^{-}$. The sum of non-electrostatic terms contributes 20 around $1 \%$ of the total solvation free energy. Hence, for all studied species we only retained the electrostatic term in CPCM computations and we expect that some error cancellations will occur.

For $\operatorname{At}(\mathrm{x})^{+}, \mathrm{X}^{-}$and $\operatorname{At}(\mathrm{x}) \mathrm{X}_{m}^{1-m}$ species, the solvation free 25 energies were first determined by CPCM-UAKS calculations at the B3LYP/mAVDZ level of theory (scalar ECP10MDF and ECP60MDF pseudopotentials were used for $\mathrm{Br}$ and $\mathrm{At}$ atoms, respectively). Geometries of the molecular species were optimized in gas-phase and in presence of the solvent. A 30 second scheme was also used to determine solvation free energies based on CPCM-UAHF calculations. In this case, only single point $\mathrm{HF} / \mathrm{mAVDZ}$ energy computations were performed on previously optimized geometries at the $\mathrm{B} 3 \mathrm{LYP} / \mathrm{mAVDZ}$ level of theory and in presence of the 35 solvent.

\section{Results and discussion}

\section{Experimental results}

Fig. 1 displays the distribution of the $\mathrm{AtO}^{+}$species in a biphasic aqueous-toluene solution as a function of $\mathrm{Cl}^{-}$and $\mathrm{Br}^{-}$ 40 ligand concentrations. The grey dashed and black solid lines are based on modeling using the parameters (complexation constants) gathered in Table 2. Ligand concentrations lower

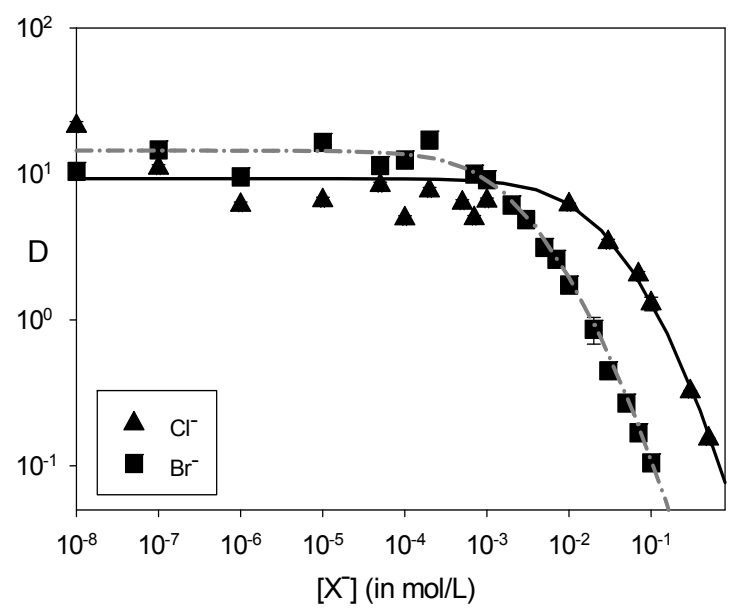

Fig. $2 \mathrm{At}^{+}$interaction with $\mathrm{Cl}^{-}$and $\mathrm{Br}^{-}$in a biphasic aqueous-toluene system. The distribution coefficient $(D)$ is plotted as a function of ligand concentration: $\mathrm{Cl}^{-}$(triangles) and $\mathrm{Br}^{-}$(squares). The curves correspond to modeling performed with CHESS using the parameters given in Table 2

15 (grey dashed line for $\mathrm{AtO}^{+} / \mathrm{Cl}^{-}$system and black solid line for $\mathrm{AtO}^{+} / \mathrm{Br}^{-}$ system).

than $10^{-5} \mathrm{~mol} / \mathrm{L}$ do not affect astatine's distribution coefficients $D$. The decrease of $D$ value for $\left[\mathrm{X}^{-}\right]>10^{-5} \mathrm{~mol} / \mathrm{L}$ ${ }_{45}$ is an evidence of $\mathrm{AtO}^{+}$complexation by $\mathrm{X}^{-}$in aqueous solution. Analyzing the dependence of $D$ values on $\mathrm{X}^{-}$ concentration yields the number and speciation of the species formed as well as their stability constants. ${ }^{41}$ The simulation and associated curves of Fig. 1 demonstrate that the 50 interaction of $\mathrm{AtO}^{+}$with $\mathrm{Cl}^{-}$and $\mathrm{Br}^{-}$involve the formation of both $1: 1$ and 1:2 complexes. The thermodynamic constants, $\beta_{1}$ and $\beta_{2}$, describing this interaction are reported in Table 2. The interaction constants between $\mathrm{AtO}^{+}$and $\mathrm{Br}^{-}$agree with the published data of Dreyer et al. ${ }^{70}$ obtained by electromobility 55 measurements. They found a value of $\log K_{2}$ equal to 2.4 for the reaction:

$\mathrm{AtOBr}+\mathrm{Br}^{-} \stackrel{K_{2}}{\rightleftharpoons} \mathrm{AtOBr}_{2}^{-}$

which is equal, within experimental errors, to the one calculated from $\beta_{1}$ and $\beta_{2}$, i.e. $\log K_{2}=2.3 \pm 0.4$.

60 Table 2 also includes the thermodynamic constants deduced for the interaction of the $\mathrm{At}^{+}$species with $\mathrm{Cl}^{-}$and $\mathrm{Br}^{-}$. Experimental data and simulation curves are displayed in Fig. 2. Similar results are obtained: experimental results and modeling agree when we consider the formation of a mixture ${ }_{65}$ of $\mathrm{AtBr}$ and $\mathrm{AtBr}_{2}^{-}$species. Thus, interactions between the cationic $\operatorname{At}(\mathrm{x})^{+}$species with small inorganic ligands result in the formation of two complexes with $1: 1$ and $1: 2$ 
stoichiometries. This phenomena was previously observed with thiocyanate ligand (Table 2). ${ }^{41}$ From the gathered results in Table 2, it appears that the efficiency of the $\operatorname{At}(x)^{+}$ interaction with the inorganic ligands increases in the order

${ }_{5} \mathrm{Cl}^{-}<\mathrm{Br}^{-}<\mathrm{SCN}^{-}$, regardless of the considered stoichiometry. According to the HSAB theory (Hard and Soft Acids and Bases), the astatine metallic species can be considered as soft acids.

\section{Quantum calculations}

${ }_{10}$ Computation of equilibrium constants for ligand exchange reactions

As it could be expected, the attempt to compute equilibrium constants for complexation reactions as described by equation (3) between $\operatorname{At}(\mathrm{x})^{+}$and ligands $\left(\mathrm{Cl}^{-}, \mathrm{Br}^{-}\right.$or $\left.\mathrm{SCN}^{-}\right)$were 15 unsuccessful. The theoretical predictions appear randomly qualitatively and/or quantitatively inaccurate for the complexation reaction studied ( $c f$. Table $\mathrm{S} 2$ in Supplementary Information). A more promising alternative approach for studying astatine chemistry is to consider reactions that 20 correspond to an exchange of ligands $\left(\mathrm{X}^{-}\right.$and $\left.\mathrm{Y}^{-}\right)$as follows:

$$
\begin{aligned}
& \operatorname{At}(\mathrm{x})^{+}+m \mathrm{X}^{-} \stackrel{\beta_{m \mathrm{x}}}{\rightleftharpoons} \operatorname{At}(\mathrm{x}) \mathrm{X}_{m}^{1-m} \\
& \underbrace{\operatorname{At}(\mathrm{x})^{+}+m \mathrm{Y}^{-} \underbrace{\beta_{m \mathrm{Y}}} \rightleftharpoons} \operatorname{At}(\mathrm{x}) \mathrm{Y}_{m}^{1-m}
\end{aligned}
$$

$$
\operatorname{At}(\mathrm{x}) \mathrm{X}_{m}^{1-m}+m \mathrm{Y}^{-} \stackrel{K_{\text {exc }}}{\rightleftharpoons} \operatorname{At}(\mathrm{x}) \mathrm{Y}_{m}^{1-m}+m \mathrm{X}^{-}
$$

The equilibrium constant of the exchange reactions can be obtained from the experimental constants of complexation reactions: $K_{e x c}=\beta_{m \mathrm{Y}} / \beta_{m \mathrm{x}}$. In addition, $K_{e x c}$ can be calculated 25 from the computed standard free energy change of reaction (13) in solution, $\Delta \Delta G_{s}^{*}$. As Scheme 2 shows, $\Delta \Delta G_{s}^{*}$ can be calculated from its components by introducing a thermodynamic cycle:

$$
\begin{aligned}
\Delta \Delta G_{s}^{*}=\Delta \Delta G_{g}^{\circ} & +\Delta G_{s o l}^{*}\left(\operatorname{At}(\mathrm{x}) \mathrm{Y}_{m}^{1-m}\right)+m \Delta G_{s o l}^{*}\left(\mathrm{X}^{-}\right) \\
& -\Delta G_{s o l}^{*}\left(\operatorname{At}(\mathrm{x}) \mathrm{X}_{m}^{1-m}\right)-m \Delta G_{s o l}^{*}\left(\mathrm{Y}^{-}\right)
\end{aligned}
$$

30 where $\Delta \Delta G_{g}^{\circ}$ is the change of free energy in the gas-phase; $\Delta G_{\text {sol }}^{*}\left(\operatorname{At}(\mathrm{x}) \mathrm{X}_{m}^{1-m}\right), \quad \Delta G_{\text {sol }}^{*}\left(\operatorname{At}(\mathrm{x}) \mathrm{Y}_{m}^{1-m}\right), \quad \Delta G_{\text {sol }}^{*}\left(\mathrm{X}^{-}\right) \quad$ and $\Delta G_{\text {sol }}^{*}\left(\mathrm{Y}^{-}\right)$are, respectively, the solvation free energies of $\operatorname{At}(\mathrm{x}) \mathrm{X}_{m}^{1-m}, \operatorname{At}(\mathrm{x}) \mathrm{Y}_{m}^{1-m}, \mathrm{X}^{-}$and $\mathrm{Y}^{-}$species in water. Therefore the prediction of $\Delta \Delta G_{s}^{*}$ could benefit from:

${ }_{35} 1$ bond-by-bond errors in electron correlation/relativistic contributions which partially cancel in the computed gasphase free energy, $\Delta \Delta G_{g}^{\circ}$.

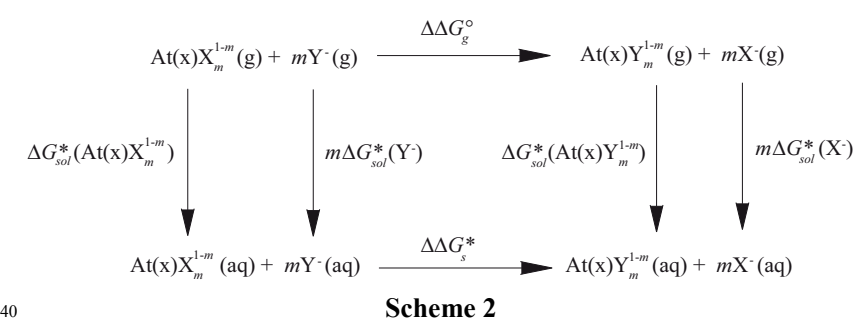

2 cancellations of systematic errors (including the neglect of non-electrostatic and SO contributions) associated with the calculations of solvation free energies, $\Delta G_{\text {sol }}^{*}$, for ionic species and for neutral species.

${ }_{45}$ More similar are the $\mathrm{X}^{-}$and $\mathrm{Y}^{-}$ligands, more the cancellations of errors will act and better will be the resulting prediction.

Table 3 reports experimental and calculated values of $\log K_{\text {exc }}$ for eight reactions corresponding to an exchange of ligands $\left(\mathrm{X}^{-}, \mathrm{Y}^{-}=\mathrm{Cl}^{-}, \mathrm{Br}^{-}\right.$and $\left.\mathrm{SCN}^{-}, m=1,2\right)$. First are given 50 the $\log K_{\text {exc }}$ values that correspond to exchange reactions in gas phase, $\Delta \Delta G_{g}^{\circ}$ being computed at the scalar-relativistic B3LYP/mAVDZ level of theory. The effects of the solvent on these reactions and $\log K_{\text {exc }}$ values are next introduced through CPCM-UAHF computations of solvation free ${ }_{55}$ energies. The final results include the contribution of SO coupling, computed at quasirelativistic B3LYP/mAVDZ level of theory, in the $\Delta \Delta G_{g}^{\circ}$ component. This separation of contributions allows for the demonstration of the following:

1 the astatine affinity with the studied ligands is totally ${ }_{60}$ reversed between the gas phase and the aqueous phase. For example, the trend predicted in gas phase for the formation of 1:1 complexes with $\mathrm{At}^{+}$is $\mathrm{SCN}^{-}<\mathrm{Br}^{-}<\mathrm{Cl}^{-}$ while the observed trend in water is $\mathrm{Cl}^{-}<\mathrm{Br}^{-}<\mathrm{SCN}^{-}$.

2 solvent effects hardly modify the $\log K_{e x c}$ values and almost always allow us to recover experimental trends: in the case of $\mathrm{AtBr}_{2}^{-}+2 \mathrm{SCN}^{-}$reaction, the reaction direction get better and the computed $\log K_{\text {exc }}$ value changes from -10.4 to 1.0 (which is close to the experimental value of $1.8 \pm 0.6)$.

703 besides the inclusion of spin-independent relativistic effects, the contribution of SO coupling must be taken into

\begin{tabular}{|c|c|c|c|c|}
\hline \multirow[b]{2}{*}{$\log \mathrm{K}_{\mathrm{exc}} \mathrm{X}^{-} / \mathrm{Y}^{-}$} & \multicolumn{2}{|c|}{$\mathrm{AtX}+\mathrm{Y}^{-} \rightleftharpoons \mathrm{AtY}+\mathrm{X}^{-}$} & \multicolumn{2}{|c|}{$\mathrm{AtOX}+\mathrm{Y}^{-} \rightleftharpoons \mathrm{AtOY}+\mathrm{X}^{-}$} \\
\hline & $\mathrm{Cl}^{-} / \mathrm{Br}^{-}$ & $\mathrm{Br}^{-} / \mathrm{SCN}^{-}$ & $\mathrm{Cl}^{-} / \mathrm{Br}^{-}$ & $\mathrm{Br}^{-} / \mathrm{SCN}^{-}$ \\
\hline Gas phase $^{a}$ & -0.5 & -7.4 & -1.3 & 12.5 \\
\hline Aqueous phase $^{b}$ & 3.2 & 1.3 & 0.9 & -0.2 \\
\hline Inclu. $\mathrm{SO}^{c}$ & 2.0 & 1.0 & 0.3 & -0.1 \\
\hline \multirow[t]{2}{*}{ Experiment } & $1.1 \pm 0.4$ & $0.8 \pm 0.4$ & $0.2 \pm 0.4$ & $0.1 \pm 0.4$ \\
\hline & \multicolumn{2}{|c|}{$\mathrm{AtX}_{2}^{-}+2 \mathrm{Y}^{-} \rightleftharpoons \mathrm{AtY}_{2}^{-}+2 \mathrm{X}^{-}$} & $\operatorname{AtOX}_{2}^{-}+2 \mathrm{Y}^{-}=$ & $\mathrm{AtOY}_{2}^{-}+2 \mathrm{X}^{-}$ \\
\hline $\log \mathrm{K}_{\mathrm{exc}} \mathrm{X}^{-} / \mathrm{Y}^{-}$ & $\mathrm{Cl}^{-} / \mathrm{Br}^{-}$ & $\mathrm{Br}^{-} / \mathrm{SCN}^{-}$ & $\mathrm{Cl}^{-} / \mathrm{Br}^{-}$ & $\mathrm{Br}^{-} / \mathrm{SCN}^{-}$ \\
\hline Gas phase $^{a}$ & -3.7 & -10.4 & -4.6 & -13.7 \\
\hline Aqueous phase $^{b}$ & 2.2 & 1.0 & 1.1 & -1.4 \\
\hline Inclu. $\mathrm{SO}^{c}$ & 1.7 & 1.1 & 0.8 & -2.0 \\
\hline Experiment & $1.8 \pm 0.4$ & $1.8 \pm 0.6$ & $2.0 \pm 0.5$ & $0.3 \pm 0.4$ \\
\hline \multicolumn{5}{|c|}{$\begin{array}{l}{ }^{a} \text { Exchange reactions in gas phase; } \Delta \Delta G_{g}^{\circ} \text { values based on scalar- } \\
\text { relativistic B3LYP/mAVDZ calculations. }{ }^{b} \text { Exchange reactions in water; } \\
\text { solvation free energies based on CPCM-UAHF calculations. }{ }^{c} \text { Exchange } \\
\text { reactions in water; } \Delta \Delta G_{g}^{\circ} \text { values based on quasirelativistic } \\
\text { B3LYP/mAVDZ calculations. }\end{array}$} \\
\hline
\end{tabular}
account during the evaluation of $\Delta \Delta G_{g}^{\circ}$ in order to reach a quantitative agreement with experimental $\log K_{\text {exc }}$ values.

75 Table 3 Computed values of $\log K_{\text {exc }}$ based on B3LYP/mAVDZ and CPCM-UAHF calculations 
The best examples are $\mathrm{AtCl}+\mathrm{Br}^{-}$and $\mathrm{AtOCl}+\mathrm{Br}^{-}$ reactions for which $\log K_{e x c}$ values are improved by 1.2 and 0.6 , respectively.

Finally, we observe that only quasirelativistic ${ }_{5} \mathrm{~B} 3 \mathrm{LYP} / \mathrm{mAVDZ}$ calculations coupled with CPCM-UAHF solvation calculations can reproduce satisfactorily the equilibrium constants of the exchange reaction. For the eight reactions studied, the mean unsigned error (MUE, calculated as the unsigned differences between the $\log K_{\text {exc }}$ values 10 obtained using the experimental stability constants gathered in Table 2 and the $\log K_{\text {exc }}$ values obtained using quantum computations) on $\log K_{\text {exc }}$ values is 0.7 , which corresponds to a MUE smaller than $1 \mathrm{kcal} \mathrm{mol}^{-1}$ on $\Delta \Delta G_{s}^{*}$, and the mean signed error (MSE, calculated as the differences between the

${ }_{15} \log K_{e x c}$ values obtained using the experimental stability constants gathered in Table 2 and the Log $K_{\text {exc }}$ values obtained using quantum computations) on $\log K_{\text {exc }}$ values is -0.4 . Two results need nevertheless more attention. In the $\mathrm{Br}^{-} / \mathrm{SCN}^{-}$ exchange reactions with $\mathrm{AtO}^{+}$and for both the 1:1 and 1:2 20 complexes, the exchange reactions seem predicted in the wrong direction $\left(\mathrm{AtO}^{+}\right.$will have a better affinity for $\mathrm{Br}^{-}$than for $\mathrm{SCN}^{-}$). The $\log K_{\text {exc }}$ values obtained from experiment, 0.1 and 0.3 respectively, show very balanced reactions between reactants $\left(\mathrm{AtBr}_{m}^{1-m}+m \mathrm{SCN}^{-}\right)$and products ${ }_{25}\left(\mathrm{AtSCN}_{m}^{1-m}+m \mathrm{Br}^{-}\right)$. Moreover, in the case of the exchange between the $1: 1$ complexes, the computed value of -0.1 is within the experimental $\log K_{\text {exc }}$ uncertainty range, $[-0.3 ;+0.5]$. The exchange reaction between the $1: 2$ complexes contrasts with the previous one, making the disagreement 30 between experiment and theory obvious: experimental and computed $\log K_{\text {exc }}$ values differ by 2.3 (which contributes by $32 \%$ and $64 \%$ to the MUE and MSE on Log $K_{\text {exc }}$, respectively). In this case, the theoretical predictions are likely to suffer from the deficiencies of the solvation models 35 used.

\section{Solvent and spin-orbit effects}

The $\log K_{\text {exc }}$ values predicted by quasirelativistic B3LYP/mAVDZ calculations coupled with CPCM-UAKS solvation calculations ( $c f$. Table S3 in Supplementary 40 Information) are in lesser agreement with the experiment: the MUE and MSE on $\log K_{\text {exc }}$ values increase to 1.5 and -1.1, respectively. This observation highlights the importance of the solvent model and CPCM-UAHF calcultations appear recommend for the computation of the solvation free energies 45 of astatine species in water.

The $\mathrm{AtOBr}^{-}+\mathrm{SCN}^{-}$reaction illustrates well the influence of solvent and SO effects on astatine chemistry. Among the possible products, the most important ones are NCSAtO, SCNAtO, NCSOAt and SCNOAt as displayed in Fig. 3. ${ }_{50}$ Table 4 reports the population of each species evaluated using a Boltzmann distribution according to the relation 15 :

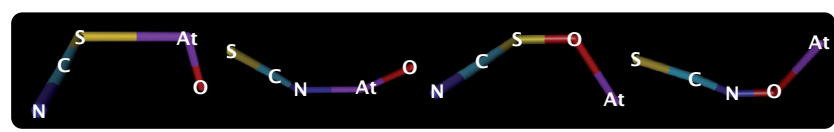

Fig. 3 Molecular structures of NCSAtO, SCNAtO, NCSOAt and ${ }_{55}$ SCNOAt species (from left to right).
Table 4 Relative Boltzmann population (\%) of NCSAtO, SCNAtO, NCSOAt and SCNOAt species computed at different levels of theory

\begin{tabular}{lcccc} 
Species & NCSAtO & SCNAtO & NCSOAt & SCNOAt \\
\hline Gas phase $^{a}$ & 0 & 0 & 100 & 0 \\
Aqueous phase $^{b}$ & 75 & 25 & 0 & 0 \\
Inclu. SO $^{c}$ & 9 & 91 & 0 & 0
\end{tabular}

${ }^{a}$ Based on gas phase free energies computed at the scalar-relativistic B3LYP/mAVDZ level of theory. ${ }^{b}$ Based on free energies corrected from 60 solvent effects contribution (CPCM-UAHF calculations). ${ }^{c}$ Gas phase free energies include $\mathrm{SO}$ effects computed at the quasirelativistic B3LYP/mAVDZ level of theory.

$p_{i}=\frac{e^{-G_{i} / R T}}{\sum_{j=1}^{4} e^{-G_{j} / R T}}$

The NCSOAt species is predicted by scalar-relativistic ${ }_{65} \mathrm{~B} 3 \mathrm{LYP} / \mathrm{mAVDZ}$ calculations as the predominant isomer in gas phase, its relative population approaching $100 \%$. Solvent effects on the distribution of the four isomers is huge. If the solvation free energies are estimated from CPCM-UAHF calculations, the NCSOAt species vanishes while the SCNAtO 70 and NCSAtO isomers rise to a population of $25 \%$ and $75 \%$, respectively. The final results include the contribution of SO coupling, computed at the quasirelativistic B3LYP/mAVDZ level of theory, in the estimation of the free energy of the four isomers. In conjunction with CPCM-UAHF calculations, the 75 inclusion of $\mathrm{SO}$ effects reverses the relative populations of SCNAtO and NCSAtO species: astatine appears to have a better affinity for the $\mathrm{N}$ atom than for the $\mathrm{S}$ atom. The predominant species is then SCNAtO, with a predicted relative population of $91 \%$, while NCSAtO represents $9 \%$ of 80 the isomers distribution (the remaining two species are negligible). These results show how the solvent and the relativistic effects due to spin-orbit coupling strongly influence the elemental astatine chemistry at a molecular level.

\section{${ }_{85}$ Conclusions}

The stability constants in water between inorganic ligands $\left(\mathrm{Cl}^{-}, \mathrm{Br}^{-}\right.$and $\left.\mathrm{SCN}^{-}\right)$and $\mathrm{At}^{+}$and $\mathrm{AtO}^{+}$species were measured using a competition method. For each reaction, both 1:1 and 1:2 complexes are evidenced. The two astatine forms exhibit a 90 better affinity for $\mathrm{SCN}^{-}$than $\mathrm{Br}^{-}$, with $\mathrm{Cl}^{-}$being the weakest ligand. The experimental trends regarding the thermodynamic constants can be reproduced qualitatively and quantitatively using an especially cost-effective computational methodology. Besides the treatment of the scalar relativistic effects, the 95 leading spin-dependent effect, i.e. the spin-orbit coupling, must be taken into account at least within the one-electron approximation. The presented methodology is based on (i) two-component B3LYP calculations using a small-core pseudopotential together with an enhanced valence double 100 zeta basis set for At, and (ii) solvation calculations using the CPCM continuum model in conjunction with specific astatine cavities. The MUE and MSE on computed $\log K$ values are 0.7 and -0.4 , respectively. The obtained agreement validates 
the theoretical calculations and strengthens the reliability of the experimental methodology. Theoretical investigations have shown that the astatine chemistry is largely modified by spin-orbit coupling and solvent effects. We believe that the 5 presented computational methodology is accurate enough to gain an insight into the astatine reactions at a molecular level.

\section{Acknowledgment}

We thank the "Agence Nationale de la Recherche" (grants ANR-JCJC06 137852 and ANR-2010-BLAN-0807), the 10 "Cancéropôle du Grand Ouest", and the European Commission FP7 Collaborative Project Programme (TARCC contract $n^{\circ}$ HEALTH-F2-2007-201962) for financial support; CEMTHI for the production of At-211; and CNRS and the "Région Pays de la Loire" for the grant allocated to J.C. The 15 authors are also grateful to Prof. Andrei Zaitsevskii and Elena Rykova for helpful discussions about astatine basis sets. This work was performed using HPC resources from GENCICINES/IDRIS (Grant 2010-x2010085117) and CCIPL (Centre de Calcul Intensif des Pays de la Loire).

\section{${ }_{20}$ References}

a Laboratoire CEISAM, UMR CNRS 6230, Université de Nantes, 2 Rue de la Houssinière, BP 92208, 44322 Nantes Cedex 3, France. Fax: +33 251 125 567; Tel: +33 251125 571; E-mail: nicolas.galland@univnantes.fr

$25{ }^{b}$ Laboratoire SUBATECH, IN2P3/CNRS/EMN Nantes/Université de Nantes, 4 rue A. Kastler, BP 20722, 44307 Nantes Cedex 03, France. Fax: +33251858 479; Tel: +33251858 420; E-mail:

montavon@subatech.in2p3.fr

$\dagger$ Electronic Supplementary Information (ESI) available: Calculated 30 spectroscopic constants of $\mathrm{At}$, HAt and $\mathrm{At}_{2}$ species from literature (Table S1); computed equilibrium constants for three complexation reactions (Table S2); computed exchange equilibrium constants based on CPCM-UAKS solvation calculations (Table S3); the modified aug-ccpVDZ-PP astatine basis set used in this work. See 35 DOI: $10.1039 / \mathrm{b} 000000 \mathrm{x} /$

1. M. R. McDevitt, G. Sgouros, R. D. Finn, J. L. Humm, J. G. Jurcic, S. M. Larson and D. A. Scheinberg, Eur. J. Nucl. Med., 1998, 25, 1341 1351.

2. M. R. Zalutsky, D. A. Reardon, G. Akabani, R. E. Coleman, A. H.

40 Friedman, H. S. Friedman, R. E. McLendon, T. Z. Wong and D. D. Bigner, J. Nucl. Med., 2008, 49, 30-38.

3. T. G. Turkington, M. R. Zalutsky, R. J. Jaszczak, P. K. Garg, G. Vaidyanathan and R. E. Coleman, Phys. Med. Biol., 1993, 38, 11211130 .

45 4. D. S. Wilbur, Curr. Radiopharm., 2008, 1, 144-176.

5. G. Vaidyanathan and M. R. Zalutsky, Curr. Radiopharm., 2008, 1, 177-196.

6. W. Kuechle, M. Dolg, H. Stoll and H. Preuss, Mol. Phys., 1991, 74, 1245-1263.

50 7. L. Visscher, J. Styszynski and W. C. Nieuwpoort, J. Chem. Phys, 1996, 105, 1987-1994.

8. L. Visscher and K. G. Dyall, J. Chem. Phys., 1996, 104, 9040-9046.

9. Y.-K. Han, C. Bae and Y. S. Lee, J. Chem. Phys., 1999, 110, 89698975 .

55 10. T. Fleig and A. J. Sadlej, Phys. Rev. A: Gen. Phys., 2002, 65, 032506.

11. P. Norman, B. Schimmelpfennig, K. Ruud, H. J. A. Jensen and H. Agren, J. Chem. Phys., 2002, 116, 6914-6923.

12. K. A. Peterson, D. Figgen, E. Goll, H. Stoll and M. Dolg, J. Chem. Phys., 2003, 119, 11113-11123.

60 13. T. Nakajima and K. Hirao, J. Chem. Phys., 2003, 119, 4105-4111.

14. B. O. Roos, R. Lindh, P.-A. Malmqvist, V. Veryazov and P.-O. Widmark, J. Phys. Chem. A, 2004, 108, 2851-2858.
15. E. Fromager, L. Maron, C. Teichteil, J.-L. Heully, K. Faegri and K. Dyall, J. Chem. Phys., 2004, 121, 8687-8698.

65 16. A. Mitin, V. and C. van Wullen, J. Chem. Phys., 2006, 124, 64305.

17. M. K. Armbruster, W. Klopper and F. Weigend, Phys. Chem. Chem. Phys., 2006, 8, 4862-4865.

18. D. Peng, W. Liu, Y. Xiao and L. Cheng, J. Chem. Phys., 2007, 127, 104106/104101-104106/104115.

70 19. M. K. Armbruster, F. Weigend, C. van Wuellen and W. Klopper, Phys. Chem. Chem. Phys., 2008, 10, 1748-1756.

20. F. Wang, J. Gauss and C. van Wuellen, J. Chem. Phys., 2008, 129, 064113/064111-064113/064117.

21. L. Visscher, O. Visser, P. J. C. Aerts, H. Merenga and W. C. Nieuwpoort, Comput. Phys. Commun., 1994, 81, 120-144.

22. M. Abe, H. Iikura, M. Kamiya, T. Nakajima, S. Yanagisawa and T. Yanai, REL4D, (2004) University of Tokyo, Tokyo, Japan.

23. L. Visscher, H. J. A. Jensen, T. Saue, R. Bast, S. Dubillard, K. G. Dyall, U. Ekström, E. Eliav, T. Fleig, A. S. P. Gomes, T. U. Helgaker, J. Henriksson, M. Iliaš, C. R. Jacob, S. Knecht, P. Norman, J. Olsen, M. Pernpointner, K. Ruud, P. Sałek and J. Sikkema, DIRAC, (2008) see http://dirac.chem.sdu.dk.

24. M. Ilias and T. Saue, J. Chem. Phys., 2007, 126, 064102/064101064102/064109.

85 25. L. Belpassi, F. Tarantelli, A. Sgamellotti and H. M. Quiney, Phys. Rev. B, 2008, 77, 233403/233401-233403/233404.

26. C. L. Collins, K. G. Dyall and H. F. Schaefer, III, J. Chem. Phys., 1995, 102, 2024-2031.

27. E. van Lenthe, E. J. Baerends and J. G. Snijders, J. Chem. Phys., 1994, 101, 9783-9792.

28. M. Filatov and D. Cremer, Mol. Phys., 2003, 101, 2295-2302.

29. W. C. Ermler, R. B. Ross and P. A. Christiansen, Adv. Quantum Chem., 1988, 19, 139-182.

30. H. S. Lee, W. K. Cho, Y. J. Choi and Y. S. Lee, Chem. Phys., 2005, 311, 121-127.

31. E. H. Appelman, J. Phys. Chem., 1961, 65, 325-331.

32. E. H. Appelman, E. N. Sloth and M. H. Studier, Inorg. Chem., 1966, 5, 766-769.

33. Y. V. Norseev and V. A. Khalkin, J. Inorg. Nucl. Chem., 1968, 30, 3239-3243.

34. T. Do Kim, I. V. Dudova and V. A. Khalkin, Radiokhimiya, 1973 , 15, 548-553.

35. N. A. Golovkov, I. I. Gromova, M. Janicki, Y. V. Norseev, V. G. Sandukovskii and L. Vasaros, Radiochem. Radioanal. Lett., 1980, 44, 67-78

36. R. Dreyer, I. Dreyer, F. Roesch and G. J. Beyer, Radiochem. Radioanal. Lett., 1982, 54, 165-175.

37. R. Dreyer, I. Dreyer, M. Pfeiffer and F. Roesch, Radiochem Radioanal. Lett., 1983, 55, 207-213.

110 38. R. Dreyer, I. Dreyer, S. Fischer, H. Hartmann and F. Roesch, J. Radioanal. Nucl. Chem., 1985, 96, 333-341.

39. S. Fischer, R. Dreyer and S. Albrecht, J. Radioanal. Nucl. Chem., 1987, 117, 275-283.

40. J. Champion, C. Alliot, E. Renault, B. M. Mokili, M. Cherel, N. Galland and G. Montavon, J. Phys. Chem. A, 2010, 114, 576-582.

41. J. Champion, C. Alliot, S. Huclier, D. Deniaud, Z. Asfari and G. Montavon, Inorg. Chim. Acta, 2009, 362, 2654-2661.

42. G. Henriksen, S. Messelt, E. Olsen and R. H. Larsen, Appl. Radiat. Isot., 2001, 54, 839-844.

120 43. C. Alliot, M. Cherel, J. Barbet, T. Sauvage and G. Montavon, Radiochim. Acta, 2009, 97, 161-165.

44. F. Groppi, M. L. Bonardi, C. Birattari, E. Menapace, K. Abbas, U. Holzwarth, A. Alfarano, S. Morzenti, C. Zona and Z. B. Alfassi, Appl. Radiat. Isot., 2005, 63, 621-631.

125 45. F.-C. Wang, Y. V. Norseev, V. A. Khalkin and T.-N. Chao, Radiokhimiya, 1963, 5, 351-355.

46. K. Berei and L. Vasaros, Astatine Compounds, 8th edn., SpringerVerlag, Berlin, 1985.

47. T. K. Hung, M. Milanov, F. Rosch and V. A. Khalkin, Radiochim. Acta, 1989, 47, 105-108.

48. R. J. P. Williams and J. J. R. Frausto da Silva, The Natural Selection of the Chemical Elements: The Environment and Life's Chemistry, Oxford University Press, Oxford, 1996. 
49. J. van der Lee and L. De Windt, J. Contam. Hydrol., 2001, 47, 265282.

50. B. J. Colston and V. J. Robinson, J. Environ. Radioact., 1995, 29, 121-136.

5 51. T. P. Straatsma, E. Aprà, T. L. Windus, E. J. Bylaska, W. de Jong, S. Hirata, M. Valiev, M. Hackler, L. Pollack, R. Harrison, M. Dupuis, D. M. A. Smith, J. Nieplocha, T. V., M. Krishnan, A. A. Auer, E. Brown, G. Cisneros, G. Fann, H. Früchtl, J. Garza, K. Hirao, R. Kendall, J. Nichols, K. Tsemekhman, K. Wolinski, J. Anchell, D.

10 Bernholdt, P. Borowski, T. Clark, D. Clerc, H. Dachsel, M. Deegan, K. Dyall, D. Elwood, E. Glendening, M. Gutowski, A. Hess, J. Jaffe, B. Johnson, J. Ju, R. Kobayashi, R. Kutteh, Z. Lin, R. Littlefield, X. Long, B. Meng, T. Nakajima, S. Niu, M. Rosing, G. Sandrone, M. Stave, H. Taylor, G. Thomas, J. van Lenthe, A. Wong and Z. Zhang,

15 NWChem, A Computational Chemistry Package for Parallel Computers, Version 5.1.1, (2008) Pacific Northwest National Laboratory, Richland, Washington 99352-0999, USA.

52. Y. J. Choi and Y. S. Lee, J. Chem. Phys., 2003, 119, 2014-2019.

53. W. K. Cho, Y. J. Choi and Y. S. Lee, Mol. Phys., 2005, 103, $2117-$ 2122.

54. S. H. Vosko, L. Wilk and M. Nusair, Can. J. Phys., 1980, 58, 12001211.

55. C. Lee, W. Yang and R. G. Parr, Phys. Rev. B, 1988, 37, 785-789.

56. A. D. Becke, J. Chem. Phys., 1993, 98, 5648-5652.

25 57. P. J. Stephens, F. J. Devlin, C. F. Chabalowski and M. J. Frisch, J. Phys. Chem., 1994, 98, 11623-11627.

58. T. H. Dunning, Jr., J. Chem. Phys., 1989, 90, 1007-1023.

59. R. A. Kendall, T. H. Dunning, Jr. and R. J. Harrison, J. Chem. Phys., 1992, 96, 6796-6806.

30 60. D. E. Woon and T. H. Dunning, Jr., J. Chem. Phys., 1993, 98, 13581371.

61. Y.-K. Han, C. Bae, S.-K. Son and Y. S. Lee, J. Chem. Phys., 2000, 112, 2684-2691.

62. A. S. P. Gomes and L. Visscher, Chem. Phys. Lett., 2004, 399, 1-6.

35 63. M. J. Frisch, G. W. Trucks, H. B. Schlegel, G. E. Scuseria, M. A. Robb, J. R. Cheeseman, J. A. Montgomery Jr., T. Vreven, K. N. Kudin, J. C. Burant, J. M. Millam, S. S. Iyengar, J. Tomasi, V. Barone, B. Mennucci, M. Cossi, G. Scalmani, N. Rega, G. A. Petersson, H. Nakatsuji, M. Hada, M. Ehara, K. Toyota, R. Fukuda, J.

40 Hasegawa, M. Ishida, T. Nakajima, Y. Honda, O. Kitao, H. Nakai, M. Klene, X. Li, J. E. Knox, H. P. Hratchian, J. B. Cross, V. Bakken, C. Adamo, J. Jaramillo, R. Gomperts, R. E. Stratmann, O. Yazyev, A. J. Austin, R. Cammi, C. Pomelli, J. W. Ochterski, P. Y. Ayala, K. Morokuma, G. A. Voth, P. Salvador, J. J. Dannenberg, V. G.

45 Zakrzewski, S. Dapprich, A. D. Daniels, M. C. Strain, O. Farkas, D. K. Malick, A. D. Rabuck, K. Raghavachari, J. B. Foresman, J. V. Ortiz, Q. Cui, A. G. Baboul, S. Clifford, J. Cioslowski, B. B. Stefanov, G. Liu, A. Liashenko, P. Piskorz, I. Komaromi, R. L. Martin, D. J. Fox, T. Keith, M. A. Al-Laham, C. Y. Peng, A.

so Nanayakkara, M. Challacombe, P. M. W. Gill, B. Johnson, W. Chen, M. W. Wong, C. Gonzalez and P. J. A., Gaussian 03, Revision C.02, (2004) Gaussian Inc., Wallingford CT.

64. V. Barone and M. Cossi, J. Phys. Chem. A, 1998, 102, 1995-2001.

65. M. Cossi, N. Rega, G. Scalmani and V. Barone, J. Comput. Chem., 2003, 24, 669-681.

66. Y. Takano and K. N. Houk, J. Chem. Theory Comput., 2005, 1, 7178.

67. V. Barone, M. Cossi and J. Tomasi, J. Chem. Phys., 1997, 107, 32103221.

60 68. C. P. Kelly, C. J. Cramer and D. G. Truhlar, J. Phys. Chem. B, 2007, 111, 408-422.

69. C. J. Cramer, Essentials of Computational Chemistry: Theories and Models, 2nd edn., J. Wiley and Sons, Chichester, 2004.

70. I. Dreyer, R. Dreyer, V. A. Chalkin and M. Milanov, Radiochem.

65 Radioanal. Lett., 1979, 40, 145-153. 